\title{
Using Ordered Weighted Average for Weighted Averages Inflation
}

\author{
Luis F. Espinoza-Audelo, Ernesto León-Castro \\ Marycruz Olazabal-Lugo, José M. Merigó \\ and Anna M. Gil-Lafuente
}

This paper presents the ordered weighted average weighted average inflation (OWAWAI) and some extensions using induced and heavy aggregation operators and presents the generalized operators and some of their families. The main advantage of these new formulations is that they can use two different sets of weighting vectors and generate new scenarios based on the reor-dering of the arguments with the weights. With this idea, it is possible to generate new approaches that under- or overestimate the results according to the knowledge and expertise of the decision-maker. The work presents an application of these new approaches in the analysis of the inflation in Chile, Colombia, and Argentina during 2017.

Keywords: OWA operator; inflation; decision making. 


\section{Introduction}

Inflation has become an important financial indicator not only for the monetary policies but also for individuals' and enterprises' financial decisions. ${ }^{1}$ In the case of policymakers, it is important for improving their forecasting and policy choices, and in the case of the enterprises and individuals, their choices in the housing market, real expenditure decisions and macroeconomic outcomes are influenced by expected inflation. ${ }^{2,3}$

In developed countries during the 1970s and 1980s when important inflation problems were present, the main conclusion was that inflation is a major burden to economic growth. ${ }^{4}$ Additionally, recent research agrees that global factors have become a common element for the differences in the national rates. ${ }^{5,6}$ In this sense, central banks are flexible on their inflation objective in order to not limit their country's growth potential. ${ }^{7,8}$

Many models have been developed in order to find the relations in inflation, such as the relationship between openness and inflation, ${ }^{9}$ between inflation and unemployment $^{10,11}$ and between the behavior of the central bank and inflation. ${ }^{12}$ An important aspect of the central bank of each country is that these banks use different techniques in order to calculate inflation. A common element is that these banks divide the different elements of the economy, assign a specific weight to each with respect to the total inflation and calculate the change in the consumer price index monthly.

As has been explained, there is no specific formula to calculate inflation because inflation changes according to the economy of the country and the information available to the central bank. Therefore, the main problem that this paper wants to solve is to generate a proposition for different inflation scenarios that can be adapted to circumstances where the decision-makers must decide based on the information available, time pressure, lack of total knowledge of the event/data or even limited expertise on the problem. ${ }^{13}$

To accomplish this task, this paper proposes using aggregation operators, specifically the ordered weighted average (OWA) operator developed by Yager ${ }^{14}$ the main reason for using this operator is that the inflation is calculated by countries based on an argument vector and a weighting vector, and because these are the main elements of the OWA operator and its extensions, these are good operators that will provide a better understanding and more scenarios without changing the data drastically. This operator was selected because it can provide different scenarios between the maximum and the minimum results that can be observed and considered when the uncertainty is presented, and this information is helpful for the enterprises that seek to make decisions about different aspects of the enterprise, such as income, expenses, and profits.

Among the extensions of the OWA operator that has been used in the paper are the following: (a) The induced OWA (IOWA) operator, ${ }^{15}$ which provides a reordering step based on the induced values. This element will be important because 
inflation can vary according to the market where the enterprise has influence, and the weights can be assigned according to the most important aspect of the inflation that needs to be taken into account; (b) The heavy OWA (HOWA) operator, ${ }^{16}$ whose main characteristic is that it has an unbounded vector that is not limited by a sum equal to 1 . This is important when the results need to be under or overestimated with respect to the expected inflation in some markets; and (c) The ordered weighted average weighted average (OWAWA) operator. ${ }^{17}$ The advantage of this operator is the inclusion of another weighted average vector that, in this case, is important when the decision-maker believes that the weights used in each of the divisions that compose the inflation are not sufficiently accurate and seeks to include a new individual proposal that is specific for its enterprise or investment decision.

It is important to note that the application of the OWA operator in different economic and financial problems has become common among researchers, such as those in asset management ${ }^{18}$ and innovation management, ${ }^{19}$ as well as in the selection of financial products, ${ }^{20}$ the selection of supply chain partners ${ }^{21}$ alternative dispute resolution methods, ${ }^{22}$ financial decision-making,${ }^{23}$ energy policies selection, ${ }^{24}$ exchange rate forecasting, ${ }^{25,26}$ enterprise risk management, ${ }^{27}$ sales forecasting, ${ }^{28}$ R\&D projections selections, ${ }^{29,30}$ and many more. ${ }^{31}$

The aim of this paper is to present the induced heavy ordered weighted average weighted average inflation (IHOWAWAI) operator, and its simpler families, such as when it does not use a heavy weighting vector or an induced reordering step, are presented. Additionally, we present the quasi-IHOWAWAI operator using quasiarithmetic means and some of the main families of the operator. These operators are important in cases where the problem is complex, and more information will be aggregated into the results. Finally, an example using the inflation of Chile, Colombia, and Argentina during 2017 is presented in order to provide a practical means to use these new formulations.

The remainder of the paper is organized in the following way. In Sec. 2, the inflation formulas for each country and the main definitions of the OWA operator, and its extensions are presented. Section 3 presents the new propositions of inflation with OWAWA operators that is called the ordered weighted average weighted average inflation (OWAWAI) operator, and its main extensions are presented. Section 4 presents the generalized operators, its main families and a numerical example. Section 5 provides the different inflation rates for Chile, Colombia, and Argentina using different aggregation operators, and Sec. 6 summarizes the main conclusions.

\section{Preliminaries}

\subsection{Inflation formulas for some Latin American countries}

The phenomenon of inflation has given rise to uncertainty in the recent years. The traditional ideas of how inflation works have been proven not to be that accurate anymore, such is the example of economies less sensitive to domestic economic 
conditions, also known as the flattening of the Phillips curve. ${ }^{55,58,59} \mathrm{~A}$ decline in the degree of exchange rate pass-through, ${ }^{60}$ decline of the inflation based on the global commodity prices, ${ }^{61}$ are some examples. Because of that, it is necessary to generate new ways to evaluate and forecast inflation based on the information that is available and with that have a wider view of the phenomenon and make better decisions. This paper presents different aggregation operator propositions based on OWAWA operators to forecast inflation and with that generate dynamic scenarios based on the expectations, aptitude and knowledge of the decision-maker.

In Sec. 3, different countries from Latin America have been chosen to calculate their inflation, particularly, Chile, Colombia, and Argentina. The first reason to select Chile and Argentina is because they have the same dimensions for evaluating inflation but with different weights. What we want to prove is how much the results can change only by changing weights and reordering the same. Colombia was selected to be a third country of the analysis because it has some similar conditions with the other two countries but has different divisions and weights. With these selections, what we want to prove is that inflation can have a level of uncertainty and subjectivity based on how it is calculated by the country and how the weights are assigned. In the following, the ways that inflation is calculated in each of the three countries is explained.

\subsubsection{Chile}

In Chile, the calculation of the inflation is based on the determination of the Consumer Price Index (CPI) of 12 different divisions that have different associated weights. This is presented in Table 1.

Table 1. Divisions and weights used to calculate inflation in Chile. ${ }^{\mathrm{a}}$

\begin{tabular}{lr}
\hline Division & Weight (\%) \\
\hline Food and nonalcoholic beverages & 19.05855 \\
Alcoholic beverages and tobacco & 3.31194 \\
Clothing and footwear & 4.48204 \\
Housing and basic services & 13.82810 \\
Equipment and maintenance of the home & 7.02041 \\
Health & 6.44131 \\
Transportation & 14.47381 \\
Communications & 5.00064 \\
Recreation and culture & 6.76121 \\
Education & 8.08996 \\
Restaurants and hotels & 4.37454 \\
Miscellaneous goods and services & 7.15749 \\
\hline
\end{tabular}

a The data is provided by the National Institute of Statistics (INE for its acronym in Spanish) See: http://www. ine.cl/estad\%C3\%ADsticas/precios/ipc. 
To calculate the inflation, each of the divisions is compared with their previous month's value with the formula $\left(\frac{\mathrm{CPI}_{n}-\mathrm{CPI}_{n-1}}{\mathrm{CPI}_{n-1}}\right)(100)$ and, at the end, each value is multiplied by its weight and summed in order to obtain the inflation rate.

An example to calculate the inflation is the following.

Example 1. The CPIs for July and August 2018 for the 12 divisions are presented in Table 2.

The first step is to determine the inflation for each division using the formula $\left(\frac{\mathrm{CPI}_{n}-\mathrm{CPI}_{n-1}}{\mathrm{CPI}_{n-1}}\right)(100)$, and the results are as follows (see Table 3 ).

Then, each of the division's inflations are multiplied by their weights and the results can be seen in Table 4 .

Table 2. CPIs for July and August 2018.

\begin{tabular}{lrr}
\hline Division & $07-18$ & $08-18$ \\
\hline Food and nonalcoholic beverages & 124.83 & 125.42 \\
Alcoholic beverages and tobacco & 142.38 & 142.63 \\
Clothing and footwear & 78.98 & 79.42 \\
Housing and basic services & 126.52 & 127.32 \\
Equipment and maintenance of the home & 116.60 & 116.75 \\
Health & 124.92 & 124.86 \\
Transportation & 109.00 & 108.41 \\
Communications & 96.00 & 96.34 \\
Recreation and culture & 103.65 & 103.11 \\
Education & 127.22 & 127.22 \\
Restaurants and hotels & 132.97 & 133.14 \\
Miscellaneous goods and services & 126.60 & 127.21 \\
\hline
\end{tabular}

Table 3. Inflation for each division in August 2018.

\begin{tabular}{lc}
\hline Division & Inflation \\
\hline Food and nonalcoholic beverages & 0.47 \\
Alcoholic beverages and tobacco & 0.18 \\
Clothing and footwear & 0.56 \\
Housing and basic services & 0.63 \\
Equipment and maintenance of the home & 0.13 \\
Health & -0.05 \\
Transportation & -0.54 \\
Communications & 0.35 \\
Recreation and culture & -0.52 \\
Education & - \\
Restaurants and hotels & 0.13 \\
Miscellaneous goods and services & 0.48 \\
\hline
\end{tabular}


Table 4. Weighted inflation for each division in August 2018.

\begin{tabular}{lccc}
\hline Division & Inflation & Weight & Weighted inflation \\
\hline Food and nonalcoholic beverages & 0.47 & 0.19059 & 0.0901 \\
Alcoholic beverages and tobacco & 0.18 & 0.03312 & 0.0058 \\
Clothing and footwear & 0.56 & 0.04482 & 0.0250 \\
Housing and basic services & 0.63 & 0.13828 & 0.0874 \\
Equipment and maintenance of the home & 0.13 & 0.07020 & 0.0090 \\
Health & -0.05 & 0.06441 & -0.0031 \\
Transportation & -0.54 & 0.14474 & -0.0783 \\
Communications & 0.35 & 0.05001 & 0.0177 \\
Recreation and culture & -0.52 & 0.06761 & -0.0352 \\
Education & - & 0.08090 & - \\
Restaurants and hotels & 0.13 & 0.04375 & 0.0056 \\
Miscellaneous goods and services & 0.48 & 0.07157 & 0.0345 \\
\hline
\end{tabular}

Finally, all weighted inflation rates are summed and the inflation for August 2018 is 0.1585 .

\subsubsection{Colombia}

In the case of Colombia, 9 different divisions are considered, and each division has an associated weight (see Table 5).

To calculate the inflation, the same procedure that was explained in Sec. 2.1.1 applies.

\subsubsection{Argentina}

In the case of Argentina, 12 different divisions are considered, and each one has an associated weight (see Table 6). It is important to note that the divisions are the same as in Chile, but the weights are drastically different.

Table 5. Divisions and weights used to calculate inflation in Colombia. ${ }^{\mathrm{b}}$

\begin{tabular}{lc}
\hline Division & Weight $(\%)$ \\
\hline Food & 28.21 \\
Housing & 30.10 \\
Clothing & 5.16 \\
Health & 2.43 \\
Education & 5.73 \\
Recreation & 3.10 \\
Transportation & 15.19 \\
Communications & 3.72 \\
Other expenses & 6.35 \\
\hline
\end{tabular}

${ }^{\mathrm{b}}$ The information is provided by the National Administrative Department of Statistics (Dane for its acronym in Spanish) See: https://www.dane.gov.co/ index.php/estadisticas-por-tema/precios-y-costos/ indice-de-precios-al-consumidor-ipc. 
Table 6. Divisions and weights used to calculate inflation in Argentina. ${ }^{c}$

\begin{tabular}{lc}
\hline Division & Weight $(\%)$ \\
\hline Food and nonalcoholic beverages & 23.40 \\
Alcoholic beverages and tobacco & 3.30 \\
Clothing and footwear & 8.50 \\
Housing and basic services & 10.50 \\
Equipment and maintenance of the home & 6.30 \\
Health & 8.80 \\
Transportation & 11.60 \\
Communications & 2.80 \\
Recreation and culture & 7.50 \\
Education & 3.00 \\
Restaurants and hotels & 10.80 \\
Miscellaneous goods and services & 3.60 \\
\hline
\end{tabular}

${ }^{\mathrm{c}}$ The information is provided by the National Institute of Statistics and Censuses (INDEC for its acronym in Spanish) See: https://www.indec.gob.ar/nivel4_default. asp?id_tema_1=3\&id_tema_2=5\&id_tema_3=31.

To calculate the inflation, the same procedure explained in Sec. 2.1.1 applies.

As seen in the inflation calculation process, an important factor that can make the inflation change drastically is the weighting vector that is used. This can be seen in Chile and Argentina since they use the same divisions, but the weights are drastically different. In this sense, a different assignment of the weighting vector with the argument will change the results. Due to this special characteristic of the data when the inflation is calculated, the propositions for using the OWA operator and its extensions is made.

\subsubsection{Basics and extensions of the $O W A W A$ operator}

To better understand the operator that will be used to improve inflation, it is important to understand the aggregation operator that is being used in the traditional formulation and the weighted average (WA) operator. ${ }^{32,33}$ They are defined as follows.

Definition 1. A WA operator of dimension $n$ is a mapping $W A: R^{n} \rightarrow R$ that has an associated weighting vector $V$, with $v_{j} \in[0,1]$ and $\sum_{i=1}^{n} v_{i}=1$ such that the following exists:

$$
\mathrm{WA}\left(a_{1}, \ldots, a_{n}\right)=\sum_{i=1}^{n} v_{i} a_{i}
$$

where $a_{i}$ represents the argument variable.

This idea was developed further by Yager $^{14}$ by adding a reordering step in the WA operator, this new operator was called ordered weighted average (OWA) 
operator and one of its main characteristics is that it is conducive to obtaining the maximum and minimum operator. The formulation is as follows.

Definition 2. An OWA operator of dimension $n$ is a mapping $F: R^{n} \rightarrow R$ with a weight vector $w=\left[w_{1}, w_{2}, \ldots, w_{n}\right]^{T}$, where $w_{j} \in[0,1], 1 \leq i \leq n$ and $\sum_{j=1}^{n} w_{j}=1$, such that

$$
\operatorname{OWA}\left(a_{1}, a_{2}, \ldots, a_{n}\right)=\sum_{j=1}^{n} w_{j} b_{j}
$$

where $b_{j}$ is the $j$ th element that is the largest of the collection $a_{1}, a_{2}, \ldots, a_{n}$.

The OWA operator was developed further by Merigó ${ }^{17}$ with the inclusion of another weighting average vector into the formulation. ${ }^{34}$ By doing this, it is possible to include two different weighting vectors with some degree of importance for each that can help us better understand a problem or a situation. The formulation is as follows.

Definition 3. An OWAWA operator of dimension $n$ is a mapping OWAWA: $R^{n} \rightarrow R$ that has an associated weighing vector $W$ of dimension $n$ such that $w_{j} \in$ $[0,1]$ and $\sum_{j=1}^{n} w_{j}=1$ and is calculated according to the following formula:

$$
\operatorname{OWAWA}\left(a_{1}, \ldots, a_{n}\right)=\sum_{j=1}^{n} \hat{v}_{j} b_{j}
$$

where $b_{j}$ is the $j$ th largest of the $a_{i}$, each argument $a_{i}$ has an associated weight (WA) $v_{i}$ with $\sum_{i=1}^{n} v_{i}=1$ where $v_{i} \in[0,1], \hat{v}_{j}=\beta w_{j}+(1-\beta) v_{j}$ where $\beta \in[0,1]$ and $v_{j}$ is ordered according to $b_{j}$, that is, according to the $j$ th largest $a_{i}$. Also, note that if the reordering step is omitted, then the OWAWA operator becomes the weighted average weighted average (WAWA) operator.

An extension of the OWAWA operator has been accomplished by Merigó ${ }^{17}$ by adding the idea of induced ordered weighted average (IOWA) operator, ${ }^{15}$ this new formulation was called the IOWAWA operator ${ }^{35}$ and its definition is the following.

Definition 4. An IOWAWA operator of dimension $n$ is a mapping IOWAWA : $R^{n} \rightarrow R$ that has an associated weighing vector $W$ of dimension $n$ such that $w_{j} \in$ $[0,1]$ and $\sum_{j=1}^{n} w_{j}=1$, according to the following formula:

$$
\operatorname{IOWAWA}\left(\left\langle u_{1}, a_{i}\right\rangle, \ldots,\left\langle u_{n}, a_{n}\right\rangle\right)=\sum_{j=1}^{n} \hat{v}_{j} b_{j},
$$

where $b_{j}$ is the $a_{i}$ value of the OWA pair $\left\langle u_{i}, a_{i}\right\rangle$ that has the $j$ th largest $u_{i}, u_{i}$ is the order-inducing variable, and $a_{i}$ is the argument variable. Each argument $a_{i}$ has an associated weight (WA) $v_{i}$ with $\sum_{i=1}^{n} v_{i}=1$ where $v_{i} \in[0,1], \hat{v}_{j}=\beta w_{j}+(1-\beta) v_{j}$ where $\beta \in[0,1]$ and $v_{j}$ is ordered according to $b_{j}$, that is, according to the $j$ th largest $a_{i}$. 
It is also possible to extend the OWAWA operator if the weighting vector is unbounded, such as with the heavy OWA (HOWA) operator, ${ }^{16}$ which becomes the HOWAWA operator. In this case, the formulation is as follows.

Definition 5. A HOWAWA operator is a mapping $R^{n} \rightarrow R$ that is associated with a weight vector $w$, where $w_{j} \in[0,1]$ and $1 \leq \sum_{j=1}^{n} w_{j} \leq n$, such that the following exists:

$$
\operatorname{HOWAWA}\left(a_{1}, a_{2}, \ldots, a_{n}\right)=\sum_{j=1}^{n} w_{j} b_{j}
$$

where $b_{j}$ is the $j$ th largest $a_{i}$, and each argument $a_{i}$ has an associated weight (WA) $v_{i}$ with $1<\sum_{i=1}^{n} v_{i}<n$ or even $-\infty<\sum_{i=1}^{n} v_{i}<\infty$ where $v_{i} \in[0,1], \hat{v}_{j}=\beta w_{j}+(1-$ $\beta) v_{j}$ where $\beta \in[0,1]$ and $v_{j}$ is ordered according to $b_{j}$, that is, according to the $j$ th largest $a_{i}$.

Yager $^{16}$ indicates some characteristics of $\beta$ that can be defined as $\beta(W)=$ $(|W|-1) /(n-1)$. In this sense, if $\beta=1$, the total operator is obtained, and if $\beta=0$, then it is the usual OWA operator.

Additionally, it is possible to use the same formulation for the main characteristics of the IOWA, HOWA and OWAWA operators. ${ }^{23,36}$ These are the reordering induced step and an unbounded weighting vector with the use of two different sets of weighting vectors. The operator will be the IHOWAWA operator, and its definition is as follows.

Definition 6. An IHOWAWA operator of dimension $n$ is a mapping IHOWAWA: $R^{n} \rightarrow R$ that has an associated weighing vector $W$ of dimension $n$ such that $w_{j} \in$ $[0,1]$ and $1 \leq \sum_{j=1}^{n} w_{j} \leq n$, which is calculated according to the following formula:

$$
\operatorname{IHOWAWA}\left(\left\langle u_{1}, a_{1}\right\rangle, \ldots,\left\langle u_{n}, a_{n}\right\rangle\right)=\sum_{j=1}^{n} \hat{v}_{j} b_{j},
$$

where $b_{j}$ is the $a_{i}$ value of the OWA pair $\left\langle u_{i}, a_{i}\right\rangle$ having the $j$ th largest $u_{i}, u_{i}$ is the order-inducing variable, and $a_{i}$ is the argument variable. Each argument $a_{i}$ has an associated weight (WA) $v_{i}$ with $1<\sum_{i=1}^{n} v_{i}<n$ or even $-\infty<\sum_{i=1}^{n} v_{i}<\infty$ where $v_{i} \in[0,1], \hat{v}_{j}=\beta w_{j}+(1-\beta) v_{j}, \beta \in[0,1]$ and $v_{j}$ is ordered according to $b_{j}$, that is, according to the $j$ th largest $a_{i}$.

Among the particular cases of the IHOWAWA operator are the following:

(1) if $u_{i}=1 / n$, then the IHOWAWA operator becomes the HOWAWA operator;

(2) if $\sum_{j=1}^{n} v_{i}=1$, then the IHOWAWA operator becomes the IOWAWA operator;

(3) if both of the scenarios described below are met, then the IHOWAWA operator becomes the OWAWA operator; and

(4) if $v_{i}=1 / n$, then the IHOWAWA operator becomes the IOWAWA operator. 
These OWA operators extension will be combined with the inflation idea to propose some operators that can be used specifically to generate different inflation scenarios and in that sense through the idea of different weighting vectors or reordering of the same with the arguments it is possible to make results that are specific for a decision-maker, market, sector, company or government.

\section{Propositions of the Inflation OWAWA Operators}

\subsection{The $O W A W A$ inflation}

A particular case of the inflation is that each country has different ways to provide a result based on different factors that are important to each one. Another characteristic is that not all the countries use the same weights for the same factor, in this sense, a way to provide a better understand of the phenomenon of the inflation is by adding another weighting vector that can be specific to the characteristic of the enterprise or that market that will be evaluated and by doing that it is possible to take into the same formulation the idea of the country inflation and the specific needs of the decision-maker.

This new operator is called the ordered weighted average weighted average inflation (OWAWAI) and its definition is as follows

Proposition 1. The OWAWAI operator of dimension $n$ is a mapping $F: R^{n} \rightarrow R$ with a weight vector $w=\left[w_{1}, \ldots, w_{n}\right]^{T}$, where $w_{j} \in[0,1], 1 \leq i \leq n$ and $\sum_{i=1}^{n} w_{j}=$ $w_{1}+\cdots+w_{n}=1$ and can be defined as

$$
\operatorname{OWAWAI}\left(i_{1}, i_{2}, \ldots, i_{n}\right)=\sum_{k=1}^{n} \hat{v}_{j} h_{j},
$$

where $h_{j}$ is the $j$ th element, which is the largest of the collection $i_{1}, i_{2}, \ldots, i_{n}$. Each element of the collection represents the factors that are considered and used in order to obtain the average inflation. Each argument $i_{i}$ has an associated weight $(W A) v_{i}$ with $\sum_{i=1}^{n} v_{i}=1$ where $v_{i} \in[0,1], \hat{v}_{j}=\beta w_{j}+(1-\beta) v_{j}$, where $\beta \in[0,1]$ and $v_{j}$ is ordered according to $h_{j}$, that $i s$, according to the jth largest $i_{i}$

An extension can be obtained if an induced reordering step is done. This operator is the induced IOWAWAI and is defined as follows.

Proposition 2. The IOWAWAI operator of dimension $n$ is a mapping IOWAWA $I: R^{n} \times R^{n} \rightarrow R$ that has an associated weighting vector $W$ of dimension $n$, where the sum of the weights is 1 and $w_{j} \in[0,1]$, where an induced set of ordering variables is included $\left(u_{i}\right)$, so the formula is

$$
\operatorname{IOWAWAI}\left(\left\langle u_{1}, i_{1}\right\rangle, \ldots,\left\langle u_{n}, i_{n}\right\rangle\right)=\sum_{k=1}^{n} \hat{v}_{j} h_{j},
$$

where $h_{j}$ is the $i_{i}$ value of the OWA pair $\left\langle u_{i}, i_{i}\right\rangle$ that has the jth largest $u_{i}, u_{i}$ is the order-inducing variable, and $i_{i}$ are the inflation factors. Each argument $i_{i}$ has an 
associated weight $(W A) v_{i}$ with $\sum_{i=1}^{n} v_{i}=1$ where $v_{i} \in[0,1], \hat{v}_{j}=\beta w_{j}+(1-\beta) v_{j}$, where $\beta \in[0,1]$ and $v_{j}$ is ordered according to $h_{j}$, that is, according to the jth largest $i_{i}$.

It is important to note that another extension can be made if the weighting vector is unbounded in this sense that the heavy ordered weighted average weighted average inflation (HOWAWAI) is obtained and can be defined as follows.

Proposition 3. The HOWAWAI operator is a map $R^{n} \rightarrow R$ that is associated with a weight vector $w$, where $w_{j} \in[0,1]$ and $1 \leq \sum_{j=1}^{n} w_{j} \leq n$, such that

$$
\operatorname{HOWAWAI}\left(i_{1}, i_{2}, \ldots, i_{n}\right)=\sum_{k=1}^{n} \hat{v}_{j} h_{j},
$$

where $h_{j}$ is the jth largest element of the collection $i_{1}, i_{2}, \ldots, i_{n}$, each argument $i_{i}$ has an associated weight $(W A) v_{i}$ with $1<\sum_{i=1}^{n} v_{i}<n$ or even $-\infty<\sum_{i=1}^{n} v_{i}<\infty$ and $v_{i} \in[0,1], \hat{v}_{j}=\beta w_{j}+(1-\beta) v_{j}$ and $\beta \in[0,1]$ and $v_{j}$ ordered according to $h_{j}$, that is, according to the jth largest of the $i_{i}$.

Finally, if both of the main characteristics of Definitions 8 and 9 are included in one, formulation of the IHOWAWAI operator is done. Its definition is as follows.

Proposition 4. The IHOWA WAI operator of dimension n is a mapping IOWAWAI : $R^{n} \times R^{n} \rightarrow R$ that has an associated weighting vector $W$ of dimension $n$, with $w_{j} \in[0,1]$ and $1 \leq \sum_{j=1}^{n} w_{j} \leq n$ and an induced set of ordering variables is included $\left(u_{i}\right)$ so the formula is

$$
\operatorname{IHOWAWAI}\left(\left\langle u_{1}, i_{1}\right\rangle, \ldots,\left\langle u_{n}, i_{n}\right\rangle\right)=\sum_{k=1}^{n} \hat{v}_{j} h_{j}
$$

where $h_{j}$ is the $i_{i}$ value of the $O W A$ pair $\left\langle u_{i}, i_{i}\right\rangle$ having the jth largest $u_{i}, u_{i}$ is the orderinducing variable, and $i_{i}$ are the inflation factors. Each argument $i_{i}$ has an associated weight (WA) $v_{i}$ with $1<\sum_{i=1}^{n} v_{i}<n$ or even $-\infty<\sum_{i=1}^{n} v_{i}<\infty$ where $v_{i} \in[0,1] \hat{v}_{j}=\beta w_{j}+(1-\beta) v_{j}$, where $\beta \in[0,1]$ and $v_{j}$ is ordered according to $h_{j}$, that $i s$, according to the jth largest $i_{i}$.

The characteristics and properties of the IHOWAWAI operator are as follows.

(a) It is monotonic because if $a_{i} \geq d_{i}$, for all $i$, then $\operatorname{IHOWAWAI}\left(a_{1}, \ldots, a_{n}\right) \geq$ $\operatorname{IHOWAWAI}\left(d_{1}, \ldots, d_{n}\right)$.

(b) It is commutative because any permutation of the argument has the same evaluation.

(c) It can be bounded if the weight vector ranges from 1 to $\infty$, and if the weight vector ranges from $-\infty$ to $\infty$, then the IHOWAWAI operator is not bounded.

(d) The characteristic of the beta value explained in Definition 5 (the HOWAWA operator) also applies to the IHOWAWAI operator. 
Additionally, these characteristics are applied for all the inflation aggregation formulas (Definitions 7-9).

It is important to note that the IHOWAWAI operator has the same special cases as the IHOWAWA operator, which are as follows.

(1) If $u_{i}=1 / n$, then the IHOWAWAI operator becomes the HOWAWAI operator.

(2) If $\sum_{j=1}^{n} v_{i}=1$, then the IHOWAWAI operator becomes the IOWAWAI operator.

(3) If both of the scenarios described above are met, then the IHOWAWAI operator becomes the OWAWAI operator.

(4) If $v_{i}=1 / n$, then the IHOWAWAI operator becomes the IOWAWAI operator.

\section{Generalized IHOWAWAI Operator}

Generalized aggregation operators ${ }^{37-39}$ are useful formulations because they provide a wide range of particular cases based on quasi-arithmetic means. It is important to note that because the generalized mean is a particular case of the quasi-arithmetic means, all the formulations are based on the last one. For the inflation aggregation operator formulas, their generalized definition is as follows.

Proposition 5. The Quasi-OWAWAI operator of dimension $n$ is a mapping QuasiOWAWAI: $R^{n} \rightarrow R$ with a weight vector $w=\left[w_{1}, \ldots, w_{n}\right]^{T}$, where $w_{j} \in[0,1]$, $1 \leq i \leq n$ and $\sum_{i=1}^{n} w_{j}=w_{1}+\cdots+w_{n}=1$. It can be defined as

$$
\text { Quasi - OWAWAI } \left.\left(i_{1}, i_{2}, \ldots, i_{n}\right)=g^{-1} \sum_{k=1}^{n} \hat{v}_{j} g\left(h_{j}\right)\right) \text {, }
$$

where $h_{j}$ is the jth element, the largest of the collection $i_{1}, i_{2}, \ldots, i_{n}$ and each element of the collection represents the factors taken into account in the inflation that are used in order to obtain the average inflation, each argument $i_{i}$ has an associated weight $(W A) v_{i}$ with $\sum_{i=1}^{n} v_{i}=1$ and $v_{i} \in[0,1], \hat{v}_{j}=\beta w_{j}+(1-\beta) v_{j}$ and $\beta \in[0,1]$ and $v_{j}$ are ordered according to $h_{j}$, that $i s$, according to the jth largest of the $i_{i}$ and $g$ (h) is a strictly continuous monotone function.

Proposition 6. The Quasi-IOWA WAI operator of dimension n is a mapping Quasi$I O W A W A I: R^{n} \times R^{n} \rightarrow R$ that has an associated weighting vector $W$ of dimension $n$, where the sum of the weights is 1 and $w_{j} \in[0,1]$, where an induced set of ordering variables is included $\left(u_{i}\right)$ so the formula is

$$
\text { Quasi - IOWAWAI } \left.\left(\left\langle u_{1}, i_{n}\right\rangle, \ldots,\left\langle u_{n}, i_{n}\right\rangle\right)=g^{-1} \sum_{k=1}^{n} \hat{v}_{j} g\left(h_{j}\right)\right),
$$

where $h_{j}$ is the $i_{i}$ value of the OWA pair $\left\langle u_{i}, i_{i}\right\rangle$ that has the jth largest $u_{i}, u_{i}$ is the orderinducing variable, and $i_{i}$ are the inflation factors. Each argument $i_{i}$ has an associated weight $(W A) v_{i}$ with $\sum_{i=1}^{n} v_{i}=1$ where $v_{i} \in[0,1], \hat{v}_{j}=\beta w_{j}+(1-\beta) v_{j}$ where $\beta \in[0,1]$ and $v_{j}$ is ordered according to $h_{j}$, that is, according to the jth largest $i_{i}$. In addition, $g(h)$ is a strictly continuous monotone function. 
Proposition 7. The Quasi-HOWAWAI operator is a mapping Quasi-HOWAWAI : $R^{n} \rightarrow R$ that is associated with a weight vector $w$, with $w_{j} \in[0,1]$ and $1 \leq \sum_{j=1}^{n} w_{j} \leq n$, such that

$$
\text { Quasi - } \left.\operatorname{HOWAWAI}\left(i_{1}, i_{2}, \ldots, i_{n}\right)=g^{-1} \sum_{k=1}^{n} \hat{v}_{j} g\left(h_{j}\right)\right),
$$

where $h_{j}$ is the jth largest element of the collection $i_{1}, i_{2}, \ldots, i_{n}$, each argument $i_{i}$ has an associated weight $(W A) v_{i}$ with $1<\sum_{i=1}^{n} v_{i}<n$ or even $-\infty<\sum_{i=1}^{n} v_{i}<\infty$ and $v_{i} \in$ $[0,1], \hat{v}_{j}=\beta w_{j}+(1-\beta) v_{j}$ and $\beta \in[0,1]$ and $v_{j}$ ordered according to $h_{j}$, that is, according to the jth largest of the $i_{i}, g(h)$ is a strictly continuous monotone function.

Proposition 8. The Quasi-IHOWAWAI operator of dimension $n$ is a mapping Quasi-IOWAWAI : $R^{n} \times R^{n} \rightarrow R$ that has an associated weighting vector $W$ of dimension $n$, with $w_{j} \in[0,1]$ and $1 \leq \sum_{j=1}^{n} w_{j} \leq n$ and an induced set of ordering variables is included $\left(u_{i}\right)$ so the formula is

$$
\text { Quasi - IHOWAWAI } \left.\left(\left\langle u_{i}, i_{1}\right\rangle, \ldots,\left\langle u_{n}, i_{n}\right\rangle\right)=g^{-1} \sum_{k=1}^{n} \hat{v}_{j} g\left(h_{j}\right)\right) \text {, }
$$

where $h_{j}$ is the $i_{i}$ value of the OWA pair $\left\langle u_{i}, i_{i}\right\rangle$ that has the jth largest $u_{i}, u_{i}$ is the orderinducing variable, and $i_{i}$ are the inflation factors. Each argument $i_{i}$ has an associated weight $(W A) \quad v_{i}$ with $1<\sum_{i=1}^{n} v_{i}<n$ or even $-\infty<\sum_{i=1}^{n} v_{i}<\infty$ where $v_{i} \in$ $[0,1], \hat{v}_{j}=\beta w_{j}+(1-\beta) v_{j}$ where $\beta \in[0,1]$ and $v_{j}$ is ordered according to $h_{j}$, that is, according to the jth largest $i_{i}$. In addition, $g(h)$ is a strictly continuous monotonic function.

It is important to note that with the Quasi-IHOWAWAI operator, we can provide further variations of the IHOWAWAI operator, and such variations are presented in Table 7.

\begin{tabular}{|c|c|}
\hline Particular case & Quasi-IHOWAWAI \\
\hline$g(b)=b^{\lambda}$ & Generalized IHOWAWAI \\
\hline$g(b)=b$ & IHOWAWAI \\
\hline$g(b)=b^{2}$ & $\begin{array}{l}\text { Induced heavy ordered weighted average weighted quadratic average inflation } \\
\text { (IHOWAWQAI) }\end{array}$ \\
\hline$g(b) \rightarrow b^{\lambda}$, for $\lambda \rightarrow 0$ & $\begin{array}{l}\text { Induced heavy ordered weighted average weighted geometric average } \\
\text { (IHOWAWGAI) }\end{array}$ \\
\hline$g(b)=b^{-1}$ & $\begin{array}{l}\text { Induced heavy ordered weighted average weighted harmonic average inflation } \\
\text { (IHOWAWHAI) }\end{array}$ \\
\hline$g(b)=b^{3}$ & $\begin{array}{l}\text { Induced heavy ordered weighted average weighted cubic average inflation } \\
\quad \text { (IHOWAWCAI) }\end{array}$ \\
\hline$g(b) \rightarrow b^{\lambda}$, for $\lambda \rightarrow \infty$ & Heavy maximum \\
\hline$g(b) \rightarrow b^{\lambda}$, for $\lambda \rightarrow \infty$ & Heavy minimum \\
\hline If $v_{i}=\frac{1}{n}$ & The IHOWAWAI becomes the Induced heavy inflation \\
\hline If $u_{i}=\frac{1}{n}$ & The IHOWAWAI becomes the HOWAWAI \\
\hline
\end{tabular}

Table 7. Variations of the IHOWAWAI operator. 
Table 8. Information to calculate the inflation aggregation operator for Chile in August 2018.

\begin{tabular}{lccccc}
\hline Division & Inflation & $\begin{array}{c}\text { Official } \\
\text { weighting } \\
\text { vector }\end{array}$ & $\begin{array}{c}\text { Expert } \\
\text { weighting } \\
\text { vector }\end{array}$ & $\begin{array}{c}\text { Expert heavy } \\
\text { weighting vector }\end{array}$ & $\begin{array}{c}\text { Induced } \\
\text { vector }\end{array}$ \\
\hline Food and nonalcoholic beverages & 0.47 & 0.19059 & 0.20 & 0.22 & 5 \\
Alcoholic beverages and tobacco & 0.18 & 0.03312 & 0.05 & 0.07 & 55 \\
Clothing and footwear & 0.56 & 0.04482 & 0.10 & 0.12 & 10 \\
Housing and basic services & 0.63 & 0.13828 & 0.10 & 0.10 & 30 \\
Equipment and maintenance & 0.13 & 0.07020 & 0.05 & 0.05 & 40 \\
$\quad$ of the home & -0.05 & 0.06441 & 0.10 & 0.15 & 15 \\
Health & -0.54 & 0.14474 & 0.15 & 0.15 & 20 \\
Transportation & 0.35 & 0.05001 & 0.03 & 0.05 & 35 \\
Communications & -0.52 & 0.06761 & 0.05 & 0.05 & 45 \\
Recreation and culture & - & 0.08090 & 0.10 & 0.10 & 25 \\
Education & 0.13 & 0.04375 & 0.03 & 0.04 & 50 \\
Restaurants and hotels & 0.48 & 0.07157 & 0.04 & 0.04 & 60 \\
Miscellaneous goods and services & & & & \\
\hline
\end{tabular}

\subsection{Numerical example}

To explain the new inflation formulations, the same information that was presented in Table 4 will be used, but in this case another weighting vector, a heavy vector and an induced vector will be used. This information is presented in Table 8 .

With the information in Table 5, the different results are presented in Tables $9-12$. (Note that $\beta=40 \%$ for the original weighting vector and $\beta=60 \%$ for the expert weighting vector.)

As seen in the numerical example, the inflation was originally 0.158 using only the official weighting vector, but with the use of the different operators, the different scenarios increased the inflation from 0.153 to 0.352 , which was more than double the original estimate for the month. This is important when the experts make decisions because it is possible to generate specific results depending on the area of the enterprise.

Table 9. OWAWAI operator results.

\begin{tabular}{cccc}
\hline Inflation & Official weighting vector & Expert weighting vector & Weighted inflation \\
\hline-0.54 & 0.03312 & 0.03 & -0.017 \\
-0.52 & 0.04375 & 0.03 & -0.018 \\
-0.05 & 0.04482 & 0.04 & -0.002 \\
0 & 0.05001 & 0.2 & 0 \\
0.13 & 0.06441 & 0.05 & 0.007 \\
0.13 & 0.06761 & 0.05 & 0.007 \\
0.18 & 0.0702 & 0.05 & 0.010 \\
0.35 & 0.07157 & 0.10 & 0.031 \\
0.47 & 0.0809 & 0.10 & 0.043 \\
0.48 & 0.13828 & 0.10 & 0.055 \\
0.56 & 0.14474 & 0.10 & 0.066 \\
0.63 & 0.19059 & 0.15 & 0.105 \\
& & OWAWAI result & 0.288 \\
\hline
\end{tabular}


These new operators can be used in a practical way in order to calculate an inflation for an specific enterprise, for example, in Chile if a company's main role is sell alcohol, the impact of that item in inflation is $3.31194 \%$, in this sense, even when the prices in that sector go way higher or don't move, they will have a little impact in the total inflation and because of that it won't reflect the reality of that sector. That is why, the use of another weighting vector that can be adapted to the need of the company, following the same example, increasing the importance of alcohol, communications and transportation and decreasing to housing (for example) will generate results that can be used to toward efficient decision-making based on data obtained specific for the company and not the general one, because sometimes the data don't represent the reality of all companies and sectors.

Table 10. IOWAWAI operator results.

\begin{tabular}{cccc}
\hline Inflation & $\begin{array}{c}\text { Official } \\
\text { weighting vector }\end{array}$ & $\begin{array}{c}\text { Expert } \\
\text { weighting vector }\end{array}$ & $\begin{array}{c}\text { Weighted } \\
\text { inflation }\end{array}$ \\
\hline 0.48 & 0.07157 & 0.04 & 0.025 \\
0.18 & 0.03312 & 0.05 & 0.008 \\
0.13 & 0.04375 & 0.03 & 0.005 \\
-0.52 & 0.06761 & 0.05 & -0.030 \\
0.13 & 0.0702 & 0.05 & 0.008 \\
0.35 & 0.05001 & 0.03 & 0.013 \\
0.63 & 0.13828 & 0.10 & 0.073 \\
0 & 0.0809 & 0.10 & 0 \\
-0.54 & 0.14474 & 0.15 & -0.080 \\
-0.05 & 0.06441 & 0.10 & -0.004 \\
0.56 & 0.04482 & 0.10 & 0.044 \\
0.47 & 0.19059 & 0.20 & 0.092 \\
& & IOWAWAI result & 0.153 \\
\hline
\end{tabular}

Table 11. HOWAWAI operator results.

\begin{tabular}{cccc}
\hline Inflation & $\begin{array}{c}\text { Official } \\
\text { weighting vector }\end{array}$ & $\begin{array}{c}\text { Expert heavy } \\
\text { weighting vector }\end{array}$ & $\begin{array}{c}\text { Weighted } \\
\text { inflation }\end{array}$ \\
\hline-0.54 & 0.03312 & 0.04 & -0.020 \\
-0.52 & 0.04375 & 0.04 & -0.022 \\
-0.05 & 0.04482 & 0.05 & -0.002 \\
0 & 0.05001 & 0.05 & 0 \\
0.13 & 0.06441 & 0.05 & 0.007 \\
0.13 & 0.06761 & 0.07 & 0.009 \\
0.18 & 0.0702 & 0.10 & 0.016 \\
0.35 & 0.07157 & 0.10 & 0.031 \\
0.47 & 0.0809 & 0.12 & 0.049 \\
0.48 & 0.13828 & 0.15 & 0.070 \\
0.56 & 0.14474 & 0.15 & 0.083 \\
0.63 & 0.19059 & 0.22 & 0.131 \\
& & HOWAWAI result & 0.352 \\
\hline
\end{tabular}


Table 12. IHOWAWAI operator results.

\begin{tabular}{cccc}
\hline Inflation & $\begin{array}{c}\text { Official } \\
\text { weighting vector }\end{array}$ & $\begin{array}{c}\text { Expert heavy } \\
\text { weighting vector }\end{array}$ & $\begin{array}{c}\text { Weighted } \\
\text { inflation }\end{array}$ \\
\hline 0.48 & 0.07157 & 0.04 & 0.025 \\
0.18 & 0.03312 & 0.07 & 0.010 \\
0.13 & 0.04375 & 0.04 & 0.005 \\
-0.52 & 0.06761 & 0.05 & -0.030 \\
0.13 & 0.0702 & 0.05 & 0.008 \\
0.35 & 0.05001 & 0.05 & 0.018 \\
0.63 & 0.13828 & 0.10 & 0.073 \\
0 & 0.0809 & 0.10 & 0 \\
-0.54 & 0.14474 & 0.15 & -0.080 \\
-0.05 & 0.06441 & 0.15 & -0.006 \\
0.56 & 0.04482 & 0.12 & 0.050 \\
0.47 & 0.19059 & 0.22 & 0.098 \\
& & IHOWAWAI result & 0.171 \\
\hline
\end{tabular}

\section{Forecasting Inflation for 2017 Using Aggregation Operators for Chile, Colombia, and Argentina}

To better understand the process that is used to forecast the inflation with the OWAWAI operator and its extension, the following steps are proposed.

Step 1. Obtain the most recent CPI available for each division.

Step 2. Calculate the inflation for each division with the formula $\left(\frac{\mathrm{CPI}_{n}-\mathrm{CPI}_{n-1}}{\mathrm{CPI}_{n-1}}\right)(100)$. Step 3. The experts should provide the weighting vector, heavy weighting vector and induced vector for each country according to their aptitude, knowledge and expectations of the future. In this step, it is important to note that if the knowledge and decision-maker will use a heavy weighting vector, it is because in their expectation of inflation there is some distortion on the official data available and that the prices have a distortion or an anomaly that will be presented in the near future. In this sense, the use of a heavy weighting vector will over or underestimate the results drastically and should be used only when there are some hints that there will be a crisis, or the governmental information is not correct.

Also, the induced vector is used when the weights want to be assigned to a specific argument and not to the traditional maximum or minimum criteria. The importance of this idea is that sometimes the decision-maker wants to put some argument with higher or lower weights according to the sector or expectation that they have. Because of this, the induced values have to be allocated based on how much the decision-maker wants an argument to weigh in the result.

Step 4. Calculate the inflation using the tradition formula, the OWAWAI operator, the IOWAWAI operator, the HOWAWAI operator and the IHOWAWAI operator. Step 5. Analyse the different scenarios in order to help the enterprises to understand how the future inflation will affect their sales, costs, expenses, and profits. 
In this paper, the information available in Chile, Colombia, and Argentina for 2017 were used, the following steps will be used.

Step 1. The CPIs for Chile, Colombia and Argentina from December 2016 to December 2017 are presented in Appendix A.1-A.3.

Step 2. The inflation for each division for 2017 is presented in Appendix A.4-A.6. Step 3. The vectors that will be used are the following (see Tables 13-15).

Step 4. The inflation is calculated using the traditional formula and the OWAWAI, IOWAWAI, HOWAWAI, and IHOWAWAI operators for each country. Additionally, the annual inflation is calculated and presented in Tables 16-18. (Note that $\beta=40 \%$ for the original weighting vector and $\beta=60 \%$ for the expert weighting vector).

As seen in the information from Tables 13-15, it is possible to obtain different scenarios regarding the inflation of each country. It is important to note that for the OWAWAI and the HOWAWAI operators, the criterion that was used is the maximization criterion, which is why the differences between the results are meaningful. The reason that the operators used that criterion was because it is important to know the worst inflation scenario that the enterprise can face. In the case of Chile, inflation is $6.39 \%$ in contrast to $2.074 \%$, in Colombia, inflation is $10.282 \%$ in comparison to $4.039 \%$, and in Argentina, inflation is $36.60 \%$ in comparison to $22.73 \%$.

Another important issue to consider is that by using the heavy vector the results are overestimated. Due to this, it is possible to analyze the results when the operator has a weighting vector equal to one and when not. In this sense, using only bounded weighting vector, Chile can have inflation from 6.029 to 1.328, Colombia from 9.96 to 3.906 and Argentina from 33.899 to 23.267 and for the operators with heavy weighting vector, the results are the following: Chile, inflation from 6.39 to 2.081, Colombia, from 10.282 to 5.291 and Argentina, from 36.6 to 25.23.

Table 13. Vectors for Chile.

\begin{tabular}{ccc}
\hline Expert weighting vector & Expert heavy weighting vector & Induced vector \\
\hline 0.20 & 0.22 & 5 \\
0.05 & 0.07 & 55 \\
0.10 & 0.12 & 10 \\
0.10 & 0.10 & 30 \\
0.05 & 0.05 & 40 \\
0.10 & 0.15 & 15 \\
0.15 & 0.15 & 20 \\
0.03 & 0.05 & 35 \\
0.05 & 0.05 & 45 \\
0.10 & 0.10 & 25 \\
0.03 & 0.04 & 50 \\
0.04 & 0.04 & 60 \\
\hline
\end{tabular}


These important changes are because there are some elements that have high inflation but their weight in the traditional inflation is not that high. Such is the case of the Alcoholic beverages and tobacco for Chile (see Appendix A.4) that has an inflation of 3.614 but its weight is 3.31194 (see Table 1). But if a maximum

Table 14. Vectors for Colombia.

\begin{tabular}{ccc}
\hline Expert weighting vector & Expert heavy weighting vector & Induced vector \\
\hline 0.3 & 0.3 & 10 \\
0.3 & 0.3 & 5 \\
0.05 & 0.1 & 15 \\
0.05 & 0.1 & 30 \\
0.05 & 0.1 & 20 \\
0.05 & 0.05 & 35 \\
0.1 & 0.1 & 25 \\
0.05 & 0.05 & 40 \\
0.05 & 0.05 & 45 \\
\hline
\end{tabular}

Table 15. Vectors for Argentina.

\begin{tabular}{ccc}
\hline Expert weighting vector & Expert heavy weighting vector & Induced vector \\
\hline 0.25 & 0.25 & 5 \\
0.05 & 0.05 & 55 \\
0.05 & 0.1 & 15 \\
0.1 & 0.15 & 20 \\
0.05 & 0.05 & 60 \\
0.1 & 0.15 & 10 \\
0.1 & 0.1 & 25 \\
0.03 & 0.03 & 50 \\
0.07 & 0.07 & 45 \\
0.05 & 0.05 & 30 \\
0.1 & 0.1 & 35 \\
0.05 & 0.05 & 40 \\
\hline
\end{tabular}

Table 16. Chilean inflation for 2017.

\begin{tabular}{cccccr}
\hline Operator & Traditional & OWAWAI & IOWAWAI & HOWAWAI & IHOWAWAI \\
\hline $01-17$ & 0.527 & 1.177 & 0.435 & 1.261 & 0.658 \\
$02-17$ & 0.221 & 0.390 & 0.276 & 0.410 & 0.185 \\
$03-17$ & 0.359 & 1.011 & 0.416 & 1.074 & 0.343 \\
$04-17$ & 0.216 & 0.432 & 0.175 & 0.462 & 0.206 \\
$05-17$ & 0.133 & 0.776 & -0.055 & 0.824 & 0.257 \\
$06-17$ & -0.424 & -0.141 & -0.546 & -0.168 & -0.434 \\
$07-17$ & 0.226 & 0.345 & 0.223 & 0.370 & 0.249 \\
$08-17$ & 0.185 & 0.488 & 0.368 & 0.526 & 0.210 \\
$09-17$ & -0.150 & 0.076 & -0.266 & 0.078 & -0.149 \\
$10-17$ & 0.562 & 0.739 & 0.419 & 0.791 & 0.469 \\
$11-17$ & 0.073 & 0.329 & -0.026 & 0.339 & -0.017 \\
$12-17$ & 0.148 & 0.405 & -0.091 & 0.423 & 0.105 \\
Annual & $\mathbf{2 . 0 7 4}$ & $\mathbf{6 . 0 2 9}$ & $\mathbf{1 . 3 2 8}$ & $\mathbf{6 . 3 9 0}$ & $\mathbf{2 . 0 8 1}$ \\
\hline
\end{tabular}


Table 17. Colombian inflation for 2017.

\begin{tabular}{cccccc}
\hline Operator & Traditional & OWAWAI & IOWAWAI & HOWAWAI & IHOWAWAI \\
\hline $01-17$ & 1.015 & 1.310 & 0.983 & 1.402 & 1.128 \\
$02-17$ & 0.966 & 2.837 & 0.942 & 2.906 & 1.277 \\
$03-17$ & 0.477 & 1.083 & 0.470 & 1.132 & 0.844 \\
$04-17$ & 0.485 & 0.678 & 0.424 & 0.716 & 0.492 \\
$05-17$ & 0.224 & 0.314 & 0.221 & 0.326 & 0.177 \\
$06-17$ & 0.131 & 0.999 & 0.185 & 1.009 & 0.288 \\
$07-17$ & -0.054 & 0.089 & -0.061 & 0.090 & -0.027 \\
$08-17$ & 0.137 & 0.215 & 0.130 & 0.222 & 0.110 \\
$09-17$ & 0.042 & 0.205 & 0.022 & 0.216 & 0.064 \\
$10-17$ & 0.018 & 0.173 & 0.014 & 0.177 & 0.047 \\
$11-17$ & 0.184 & 0.348 & 0.184 & 0.362 & 0.201 \\
$12-17$ & 0.412 & 1.709 & 0.392 & 1.725 & 0.690 \\
Annual & $\mathbf{4 . 0 3 9}$ & $\mathbf{9 . 9 6 0}$ & $\mathbf{3 . 9 0 6}$ & $\mathbf{1 0 . 2 8 2}$ & $\mathbf{5 . 2 9 1}$ \\
\hline
\end{tabular}

Table 18. Argentinian inflation for 2017.

\begin{tabular}{cccccc}
\hline Operator & Traditional & OWAWAI & IOWAWAI & HOWAWAI & IHOWAWAI \\
\hline $01-17$ & 1.662 & 2.250 & 1.504 & 2.487 & 1.597 \\
$02-17$ & 2.116 & 3.248 & 2.289 & 3.555 & 2.442 \\
$03-17$ & 2.459 & 4.546 & 3.025 & 4.816 & 3.396 \\
$04-17$ & 2.645 & 3.948 & 2.834 & 4.331 & 3.098 \\
$05-17$ & 1.433 & 1.790 & 1.418 & 1.941 & 1.564 \\
$06-17$ & 1.205 & 1.512 & 1.157 & 1.647 & 1.261 \\
$07-17$ & 1.809 & 2.469 & 1.599 & 2.720 & 1.708 \\
$08-17$ & 1.400 & 1.747 & 1.494 & 1.917 & 1.595 \\
$09-17$ & 1.902 & 2.495 & 2.051 & 2.740 & 2.322 \\
$10-17$ & 1.482 & 2.508 & 1.567 & 2.702 & 1.694 \\
$11-17$ & 1.405 & 1.655 & 1.319 & 1.786 & 1.427 \\
$12-17$ & 3.220 & 5.729 & 3.010 & 5.957 & 3.127 \\
Annual & $\mathbf{2 2 . 7 3 7}$ & $\mathbf{3 3 . 8 9 9}$ & $\mathbf{2 3 . 2 6 7}$ & $\mathbf{3 6 . 6 0 0}$ & $\mathbf{2 5 . 2 3 0}$ \\
\hline
\end{tabular}

reordering step is used, then the weights assigned to Alcoholic beverages and tobacco will be 19.05855. And by doing this, the results of the inflation will change drastically. Also, it is possible to see from Tables 13-15, that when induced values are presented, then the inflation decreases drastically. This is because the order is not based on the maximum or minimum, but based on the main idea of the decisionmaker regarding how much each division will affect his/her company.

\section{Conclusions}

The main purpose of the paper is to provide a new aggregation operator called the OWAWAI operator. This new operator is a new formulation that uses the main characteristic of the OWAWA operator to calculate inflation. Additionally, some extensions using induced values, heavy weighting vectors and a combination of both 
were developed. These extensions were called the IOWAWAI, HOWAWAI, and IHOWAWAI operators. The main characteristics of these new formulations is that they can provide new inflation scenarios that can be calculated using the expectations, knowledge, and characteristics of the market of the enterprise and, depending on the complexity of the situation or the problem, different formulations can be calculated.

These propositions are important because with the same information provided by the governments, it is possible to generate different scenarios and results by a reordering process of the weighting vector, a new weighting vector based on the expectations and knowledge of the decision-maker, or even assigning different relations between weights and arguments through induced values. With these propositions, the enterprises and decision-makers can have a wider view of the phenomenon and improve the decision-making process under uncertainty.

Additionally, the generalized OWAWAI, IOWAWAI, HOWAWAI, and IHOWAWAI operators are presented using quasi-arithmetic means. (This is accomplished because the generalized operator can be obtained as a special case of the quasi-arithmetic means). Some of the main variations of the IHOWAWAI operator are presented and the same idea can be applied to the other operators presented in the paper.

An example using Chile, Colombia, and Argentina and their data for 2017 was presented. The main idea of using three countries was to provide a better understanding that not all countries use the same formula to calculate inflation. Even when the divisions are the same, the weights that are used are different. In this sense, the idea of obtaining the maximum or the minimum operator is important to understanding the worst and the best scenarios. Additionally, the inclusion of a new weighted vector that adapts to the specifications of the decision-maker or enterprise becomes relevant. In the results, it is possible to see how the inflation can dramatically change if the maximum operator is used. For example, inflation in Chile increases from $2 \%$ to $6 \%$ (3-fold), inflation in Colombia increases from $4 \%$ to $10 \%$ and inflation in Argentina increases from 22\% to 36\%. With this information, new strategies can be implemented in order to protect the profits of the investor or enterprise.

For future research, new extensions of the OWA operator and applications ${ }^{40,56,57}$ can be derived by using the Bonferroni means, ${ }^{41,42}$ moving averages,${ }^{26}$ hesitant linguistic variables, ${ }^{43,44}$ consensus models, ${ }^{45,46}$ their application in other areas of engineering, business, economics and finance ${ }^{47-49}$ and multicriteria decision-making. ${ }^{50-54}$ 


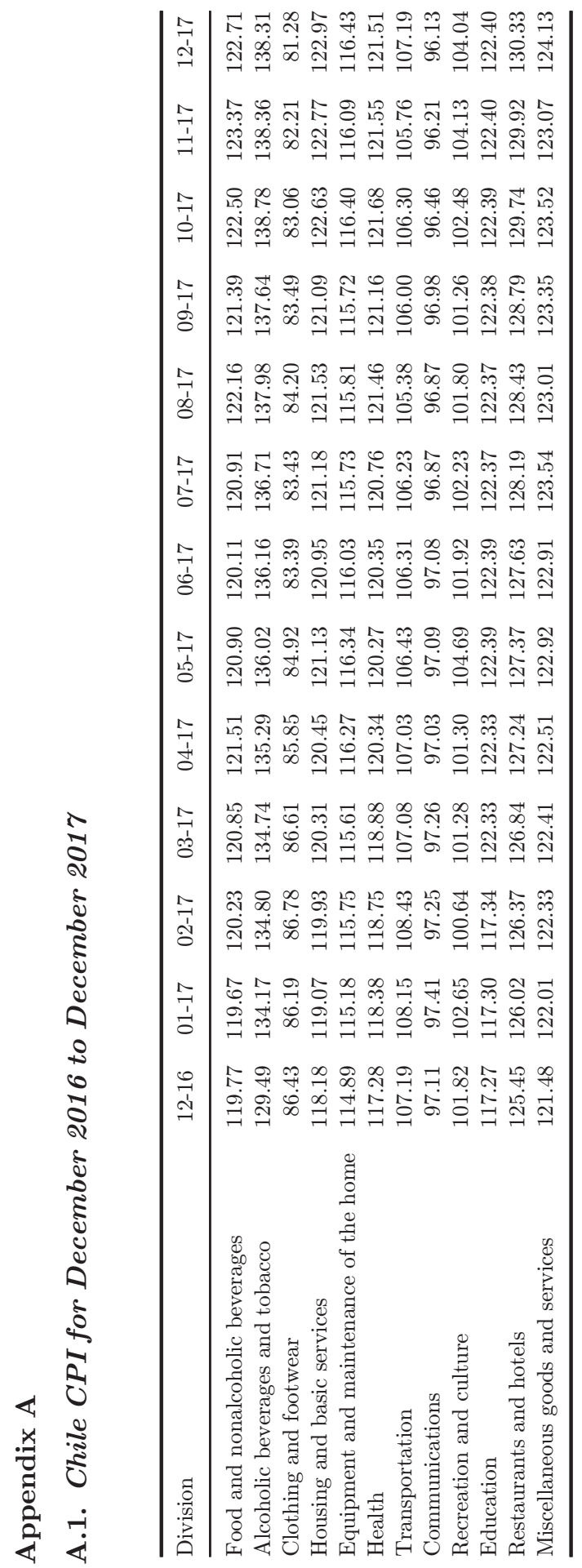



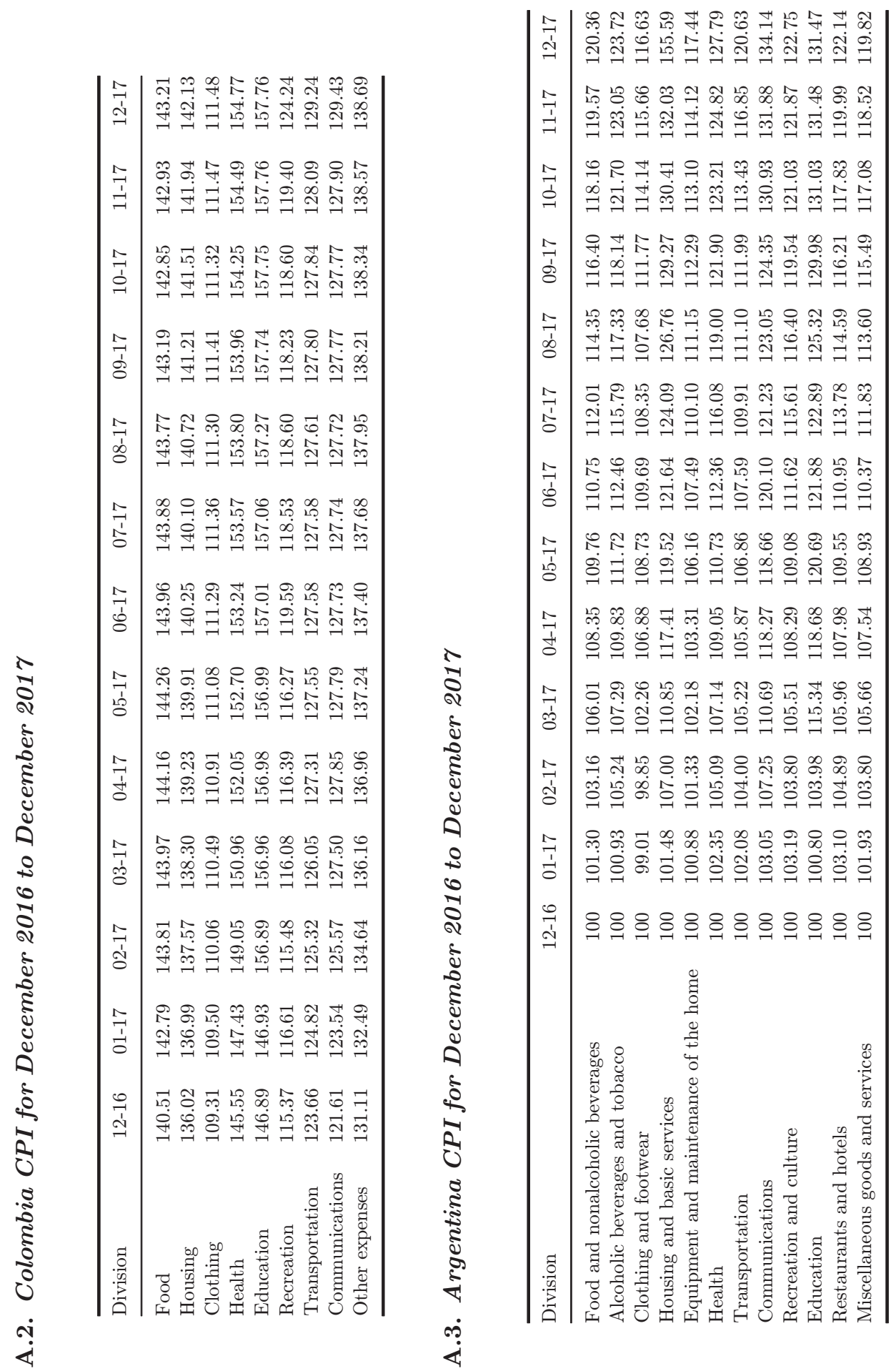

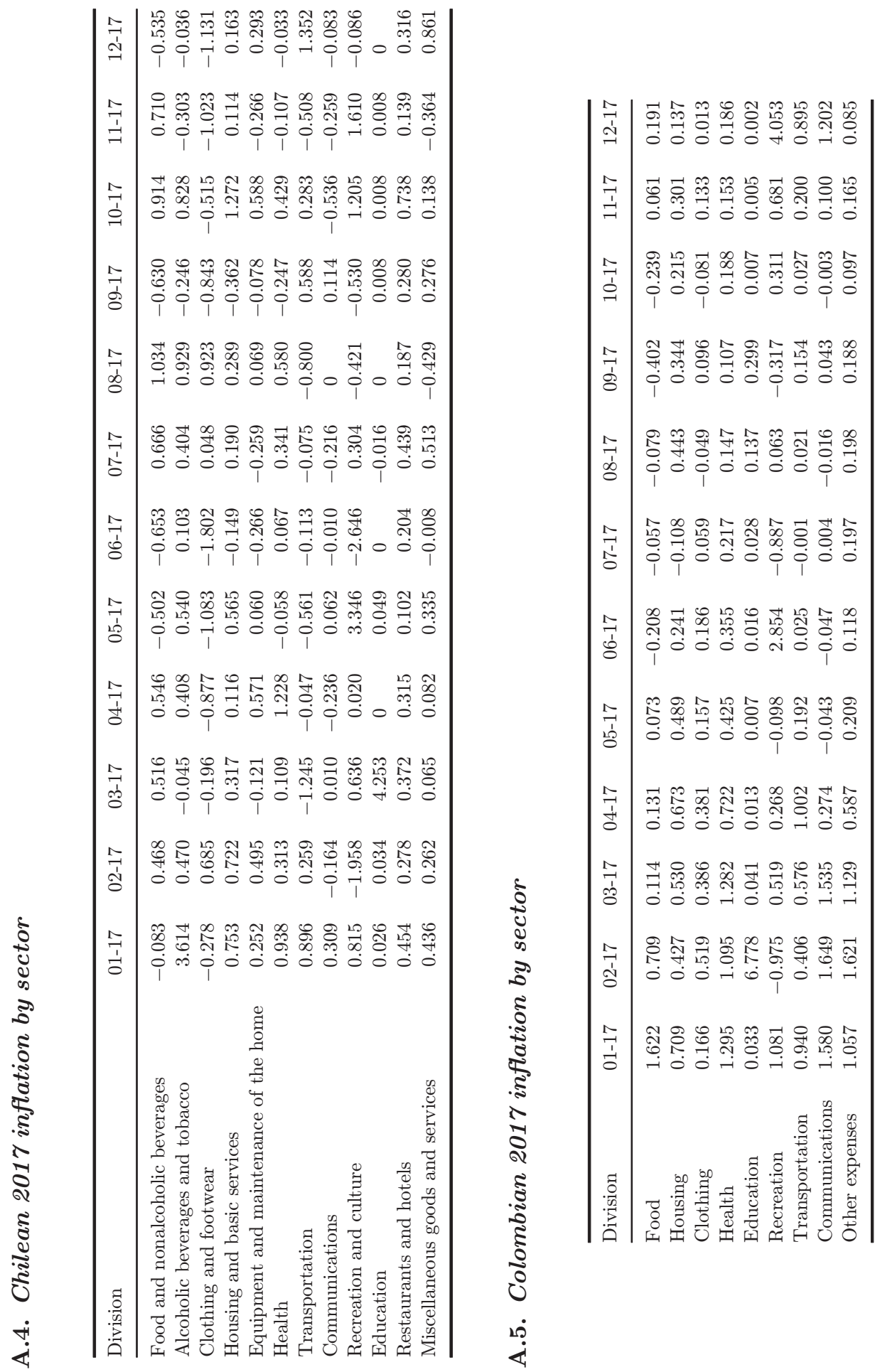


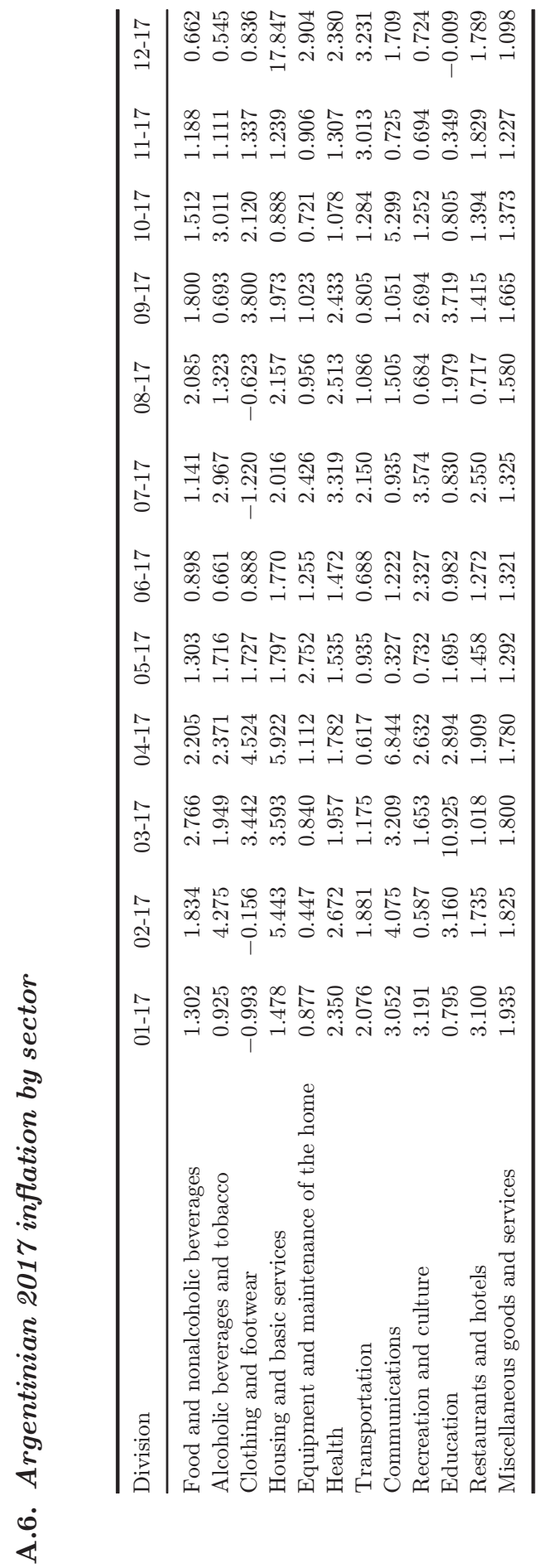




\section{References}

1. U. Malmendier and S. Nagel, Learning from inflation experiences, The Quarterly Journal of Economics 131(1) (2015) 53-87.

2. B. S. Bernanke, Inflation expectations and inflation forecasting, speech delivered at the monetary economics workshop of the National Bureau of Economic Research Summer Institute, Cambridge, Massachusetts, 2007. https://www.federalreserve.gov/newsevents/ speech/Bernanke20070710a.htm.

3. M. Woodford and C. E. Walsh, Interest and prices: Foundations of a theory of monetary policy, Macroeconomic Dynamics 9(3) (2005) 462-468.

4. F. S. Mishkin, Inflation targeting in emerging-market countries, American Economic Review 90(2) (2000) 105-109.

5. M. Ciccarelli and B. Mojon, Global inflation, The Review of Economics and Statistics 92(3) (2010) 524-535.

6. M. Parker, How global is "global inflation"?, Journal of Macroeconomics 58 (2018) 174-197.

7. F. E. Kydland and E. C. Prescott, Rules rather than discretion: The inconsistency of optimal plans, Journal of Political Economy 85(3) (1977) 473-491.

8. Z. Hayat, F. Balli and M. Rehman, Does inflation bias stabilize real growth? Evidence from Pakistan, Journal of Policy Modeling 40(6) (2018) 1083-1103.

9. D. Romer, Openness and inflation: Theory and evidence, The Quarterly Journal of Economics 108(4) (1993) 869-903.

10. P. N. Ireland, Does the time-consistency problem explain the behavior of inflation in the United States? Journal of Monetary Economics 44(2) (1999) 279-291.

11. F. J. Ruge-Murcia, The inflation bias when the central bank targets the natural rate of unemployment, European Economic Review 48(1) (2004) 91-107.

12. Z. Hayat, F. Balli, J. Obben and S. Shakur, An empirical assessment of monetary discretion: The case of Pakistan, Journal of Policy Modeling 38(5) (2016) 954-970.

13. G. W. Wei, Uncertain linguistic hybrid geometric mean operator and its application to group decision making under uncertain linguistic environment, International Journal of Uncertainty, Fuzziness and Knowledge-Based Systems 17(2) (2009) 251-267.

14. R. R. Yager, On ordered weighted averaging aggregation operators in multicriteria decisionmaking, IEEE Transactions on Systems, Man, and Cybernetics 18(1) (1988) 183-190.

15. R. R. Yager and D. P. Filev, Induced ordered weighted averaging operators, IEEE Transactions on Systems, Man, and Cybernetics, Part B (Cybernetics) 29(2) (1999) 141-150.

16. R. R. Yager, Heavy OWA operators, Fuzzy Optimization and Decision Making 1(4) (2002) 379-397.

17. J. M. Merigó, A unified model between the weighted average and the induced OWA operator, Expert Systems with Applications 38(9) (2011) 11560-11572.

18. J. M. Merigó, L. Zhou, D. Yu, N. Alrajeh and K. Alnowibet, Probabilistic OWA distances applied to asset management, Soft Computing 22(15) (2018) 4855-4878.

19. V. G. Alfaro-García, J. M. Merigó, A. M. Gil-Lafuente and J. Kacprzyk, Logarithmic aggregation operators and distance measures, International Journal of Intelligent Systems 33(7) (2018) 1488-1506.

20. J. M. Merigó and A. M. Gil-Lafuente, New decision-making techniques and their application in the selection of financial products, Information Sciences 180(11) (2010) 2085-2094. 
21. S. L. Chang, R. C. Wang and S. Y. Wang, Applying fuzzy linguistic quantifier to select supply chain partners at different phases of product life cycle, International Journal of Production Economics 100(2) (2006) 348-359.

22. L. A. Pérez-Arellano, E. León-Castro, E. Avilés-Ochoa and J. M. Merigó, Prioritized induced probabilistic operator and its application in group decision making, International Journal of Machine Learning and Cybernetics 10(3) (2019) 451-462.

23. J. M. Merigo and M. Casanovas, The uncertain generalized OWA operator and its application to financial decision making, International Journal of Information Technology 85 Decision Making 10(2) (2011) 211-230.

24. S. Zeng and Y. Xiao, A method based on topsis and distance measures for hesitant fuzzy multiple attribute decision making, Technological and Economic Development of Economy 24(3) (2018) 969-983.

25. E. León-Castro, E. A. Avilés-Ochoa and A. M. Gil-Lafuente, Exchange rate USD/ MXN forecast through econometric models, time series and HOWMA operators, Economic Computation \& Economic Cybernetics Studies $\&$ Research 50(4) (2016) 135150.

26. E. León-Castro, E. Avilés-Ochoa, J. M. Merigó and A. M. Gil-Lafuente, Heavy moving averages and their application in econometric forecasting, Cybernetics and Systems 49(1) (2018) 26-43.

27. F. Blanco-Mesa, E. León-Castro and J. M. Merigó, Bonferroni induced heavy operators in ERM decision-making: A case on large companies in Colombia, Applied Soft Computing 72 (2018) 371-391.

28. F. Blanco-Mesa, E. León-Castro, J. M. Merigó and Z. S. Xu, Bonferroni means with induced ordered weighted average operators, International Journal of Intelligent Systems 34(1) (2019) 3-23.

29. S. Zeng, C. Cao, Y. Deng and X. Shen, Pythagorean fuzzy information aggregation based on weighted induced operator and its application to R\&D projections selection, Informatica 29(3) (2018) 567-580.

30. S. Zeng, Z. Mu and T. Baležentis, A novel aggregation method for Pythagorean fuzzy multiple attribute group decision making, International Journal of Intelligent Systems 33(3) (2018) 573-585.

31. V. G. Alfaro-García, J. M. Merigó, L. Plata-Perez, G. Alfaro-Calderon and A. M. GilLafuente, Induced and logarithmic distances with multi-region aggregation operators, Technological and Economic Development of Economy 25(4) (2019) 664-692.

32. G. Beliakov, A. Pradera and T. Calvo, Aggregation Functions: A Guide for Practitioners, Vol. 221 (Springer, Heidelberg, 2007).

33. V. Torra and Y. Narukawa, Modeling Decisions: Information Fusion and Aggregation Operators (Springer Science \& Business Media, 2007).

34. J. M. Merigó, D. Palacios-Marqués and P. Soto-Acosta, Distance measures, weighted averages, OWA operators and Bonferroni means, Applied Soft Computing 50 (2017) 356-366.

35. S. Zeng, C. Llopis-Albert and Y. Zhang, A novel induced aggregation method for intuitionistic fuzzy set and its application in multiple attribute group decision making. International Journal of Intelligent Systems 33(11) (2018) 2175-2188.

36. E. León-Castro, E. Avilés and J. M. Merigó, Induced heavy moving averages, International Journal of Intelligent Systems 33(9) (2018) 1823-1839.

37. T. Calvo, G. Mayor and R. Mesiar, Aggregation Operators: New Trends and Applications (Physica-Verlag, New York, 2002).

38. J. M. Merigó and A. M. Gil-Lafuente, The induced generalized OWA operator, Information Sciences 179(6) (2009) 729-741. 
39. H. Zhao, Z. S. Xu, M. Ni and S. Liu, Generalized aggregation operators for intuitionistic fuzzy sets, International Journal of Intelligent Systems 25(1) (2010) 1-30.

40. J. Kacprzyk, R. R. Yager and J. M. Merigó, Towards human centric aggregation via the ordered weighted aggregation operators and linguistic data summaries: A new perspective on Zadeh's inspirations, IEEE Computational Intelligence Magazine 14(1) (2019) 16-30.

41. C. Bonferroni, Sulle medie multiple di potenze, Bollettino dell'Unione Matematica Italiana 5(3-4) (1950) 267-270.

42. F. Blanco-Mesa, J. M. Merigó and J. Kacprzyk, Bonferroni means with distance measures and the adequacy coefficient in entrepreneurial group theory, Knowledge-Based Systems 111 (2016) 217-227.

43. P. Wu, L. Zhou, H. Chen and Z. Tao, Additive consistency of hesitant fuzzy linguistic preference relation with a new expansion principle for hesitant fuzzy linguistic term sets, IEEE Transactions on Fuzzy Systems 27(4) (2018) 716-730.

44. P. Wu, J. Zhu, L. Zhou and H. Chen, Local feedback mechanism based on consistencyderived for consensus building in group decision making with hesitant fuzzy linguistic preference relations, Computers $\&$ Industrial Engineering 137 (2019) 106001.

45. L. G. Zhou and H. Y. Chen, Continuous generalized OWA operator and its application to decision making, Fuzzy Sets and Systems 168(1) (2011) 18-34.

46. P. Wu, Q. Wu, L. Zhou, H. Chen and H. Zhou, A consensus model for group decision making under trapezoidal fuzzy numbers environment, Neural Computing and Applications 31(2) (2019) 377-394.

47. S. Laengle, G. Loyola and J. M. Merigó, Mean-variance portfolio selection with the ordered weighted average, IEEE Transactions on Fuzzy Systems 25(2) (2017) 350-362.

48. S. Maldonado, J. Merigó and J. Miranda, Redefining support vector machines with the ordered weighted average, Knowledge-Based Systems 148 (2018) 41-46.

49. L. A. Zadeh, A. M. Abbasov, R. R. Yager, S. N. Shahbazova and M. Z. Reformat (Eds.), Recent Developments and New Directions in Soft Computing (Springer International Publishing, 2014).

50. G. Kou, D. Ergu, C. Lin and Y. Chen, Pairwise comparison matrix in multiple criteria decision making, Technological and Economic Development of Economy 22(5) (2016) $738-765$.

51. G. Kou, Y. Lu, Y. Peng and Y. Shi, Evaluation of classification algorithms using MCDM and rank correlation, International Journal of Information Technology \& Decision Making 11(1) (2012) 197-225.

52. G. Kou, Y. Peng and G. Wang, Evaluation of clustering algorithms for financial risk analysis using MCDM methods, Information Sciences 275 (2014) 1-12.

53. G. Kou, P. Yang, Y. Peng, F. Xiao, Y. Chen and F. E. Alsaadi, Evaluation of feature selection methods for text classification with small datasets using multiple criteria decision-making methods, Applied Soft Computing 86 (2020) 105836.

54. H. Zhang, G. Kou and Y. Peng, Soft consensus cost models for group decision making and economic interpretations, European Journal of Operational Research 277(3) (2019) 964-980.

55. A. Cukierman and S. Gerlach, The inflation bias revisited: Theory and some international evidence, The Manchester School 71(5) (2003) 541-565.

56. R. R. Yager, The power average operator, IEEE Transactions on Systems, Man, and Cybernetics-Part A: Systems and Humans 31(6) (2001) 724-731.

57. L. Zhou and H. Chen, Generalized ordered weighted proportional averaging operator and its application to group decision making, Informatica 25(2) (2014) 327-360.

58. International Monetary Fund (IMF). How Has globalization affected inflation? World Economic Outlook (2006), pp. 97-134. 
59. International Monetary Fund (IMF). The dog that didn't bark: Has inflation been muzzled or was it just sleeping? In World Economic Outlook: Hopes, Realities, Risks (International Monetary Fund, Washington, DC, 2013), pp. 79-96.

60. W. R. White, Globalisation and the Determinants of Domestic Inflation. BIS Working Paper No. 250, 2008, pp. 1-29.

61. J. S. Davis, Central bank credibility and the persistence of inflation and inflation expectations. Federal Reserve Bank of Dallas. Working Paper No. 117, 2012, pp. 1-42. 